\title{
A LÍNGUA DE SINAIS NA CONCEPÇÃO DE OTORRINOLARINGOLOGISTA \\ E FONOAUDIÓLOGO
}

\author{
SIGN LANGUAGE FROM THE VIEWPOINT OF AN \\ OTORHINOLARYNGOLOGIST AND SPEECH-LANGUAGE PATHOLOGIST
}

\author{
LA LENGUA DE SEÑAS EN LA CONCEPCIÓN
}

DELOTORRINOLARINGOLOGISTA Y FONOAUDIOLOGO

\author{
Neuma Chaveiro* \\ Claudney Maria de Oliveira Silva** \\ Ednéia Aparecida de Paula Almeida*** \\ Kelle Cristina Ferreira \\ Layla Silva Souza \\ Raquel Silva Pereira de Araújo \\ Renato Vieira Rodrigues
}

\section{Resumo}

Este artigo tem como objetivos investigar a orientação dos médicos otorrinolaringologistas e fonoaudiólogos sobre a aquisição de língua e também a concepção desses profissionais sobre a língua de sinais diante de um diagnóstico de surdez. A pesquisa, de abordagem qualitativa, foi realizada por meio de uma entrevista estruturada e questionário com perguntas abertas. A análise dos dados demonstrou que há divergência de opiniões quanto à orientação dada às famílias dos pacientes. Para o otorrinolaringologista, dependendo do tipo e do grau de surdez, é possível o uso do aparelho auditivo ou a realização do implante coclear, deixando clara a sua opção por uma orientação de cunho oralista, enquanto a fonoaudióloga recomenda o uso da Libras.

Palavras-chave: língua de Sinais, Surdo, diagnóstico de surdez.

\section{Introdução}

A língua de sinais é a língua natural das pessoas surdas, ou seja, a língua que pode ser adquirida pelas crianças, naturalmente e de forma inconsciente, a partir da interação com seus falantes. Um ambiente linguístico favorável propicia sua aquisição

\footnotetext{
* Doutora em Ciências da Saúde pela Universidade Federal de Goiás. Professora do Curso de Letras: Libras da Faculdade de Letras da UFG; E-mail: neumachaveiro@gmail.com .

** Doutoranda em Linguística pela Universidade Federal de Goiás. Professora do Curso de Letras: Libras da Faculdade de Letras da UFG; E-mail: claudney@terra.com.br .

*** Graduandos do Curso de Letras: Libras da Universidade Federal de Goiás- UFG em pesquisa da Prática como Componente Curricular.
} 
com naturalidade e rapidez, oportunizando aos surdos o desenvolvimento cognitivo, bem como todas as suas necessidades comunicativas (GOLDFELD, 2002). Por outro lado, para que o surdo adquira a língua oral, é necessária a intervenção de um fonoaudiólogo para a realização de terapias de fala, um procedimento que demanda treino e esforço por longos anos.

Entretanto, mesmo que o surdo consiga oralizar, ou seja, utilizar a modalidade de língua oral para se comunicar e se expressar, ou ainda, realizar leitura labial, que é a técnica de ler e interpretar os movimentos dos lábios do interlocutor, através da leitura orofacial, que é utilizada por alguns surdos, é imprescindível que adquira a língua de sinais, sua língua natural com a qual ele terá condições de internalizar conceitos e se apropriar da linguagem, o que lhe permitirá desta forma expressar a sua subjetividade e identidade enquanto surdo (SKLIAR, 1998). Dada a importância da língua de sinais na vida dos surdos, essa pesquisa investiga a orientação de um otorrinolaringologista e uma fonoaudióloga sobre a aquisição de língua e a concepção desses profissionais sobre a língua de sinais. São objetivos desse trabalho, investigar a concepção de otorrinolaringologistas e fonoaudiólogos sobre a Língua de Sinais e qual a orientação sobre a aquisição de língua geralmente dada por esses profissionais aos pais ou responsáveis da criança diante de um diagnóstico de surdez durante um atendimento clínico.

Sabe-se que quando a família descobre que um filho é surdo, sente-se abalada, fragilizada, e por isso a orientação dada nesse momento é fundamental. Os profissionais encarregados de conduzir a fase inicial de um diagnóstico de surdez têm um poder decisivo no desenvolvimento e aquisição de língua dos surdos. A família é completamente influenciada pela orientação que lhe for dada, e por isso esse momento requer atenção dos pesquisadores, especialmente os da área da aquisição da linguagem, visando garantir à criança surda a aquisição de uma língua natural (GOLDFELD, 2002). Quanto mais cedo as crianças adquirirem a Libras, mais rapidamente terão condições de expor seus sentimentos, necessidades e desejos com naturalidade. E mais do que isso, a Língua de Sinais lhes possibilitará a estruturação do pensamento, da cognição, da socialização, que resultará no desenvolvimento da linguagem (MONTES; SANTOS, 2004). 
Por muitos anos os surdos foram privados de utilizar sua língua natural e isto, sem dúvida, lhes trouxe grandes prejuízos, principalmente no que diz respeito aos aspectos social, emocional e cognitivo. Essa circunstância deixou os surdos, no tocante ao desenvolvimento educacional, aquém do esperado, em relação aos alunos ouvintes. Esse período é historicamente conhecido como Oralismo, difundido a partir de 1880 no Congresso de Milão. Nesse evento mundial, importante na história da educação dos surdos, decidiu-se que os educadores deveriam adotar, exclusivamente, a modalidade oral no processo de ensino dos alunos surdos. Para impor essa metodologia, foram utilizados severos métodos de fonoarticulação, treinamentos que objetivavam desenvolver a fala, envolvendo todos os elementos corporais que interferem na produção dos fonemas, como a respiração, os órgãos (estruturas) fonoarticulatórios e o relaxamento da musculatura, além da proibição de uso de sinalização, por parte dos surdos, e de intenso treinamento labial.

No decorrer do século XX, foram desenvolvidas novas tecnologias para dar suporte ao Oralismo, entre eles os aparelhos de amplificação sonora. Nessa abordagem, algumas das principais formas de trabalho eram: estimulação auditiva, com aproveitamento dos resíduos auditivos dos surdos visando à discriminação dos sons; o uso do método de língua natural,o qual se baseia no pressuposto de que as crianças devem aprender a falar através da atividade, considerando-se que, no Oralismo, as crianças são encorajadas a fazer perguntas através da fala. O Oralismo também utiliza treinamento de leitura orofacial e de fala, além do método unissensorial ou abordagem aural, também conhecido como abordagem acupédica, e se refere a um programa de reabilitação para a criança surda, que enfatiza o treinamento auditivo sem nenhum ensino formal de leitura orofacial e exige o envolvimento da família (HONORA; FRIZANCO, 2009).

Na década de 1960, questionamentos sobre a eficácia do Oralismo fizeram com que a corrente oralista perdesse força e daí surgiu a Comunicação Total, que consistia basicamente na utilização de vários tipos de recursos para garantir à criança surda aquisição de linguagem, tais como sinais naturais e artificiais, alfabeto manual, gestos, leitura labial e mímica. No entanto, observou-se também que, mesmo com a Comunicação Total, o surdo não apresentava um desenvolvimento cognitivo satisfatório. Conforme ressaltam Litching, Couto e Carnio (2000, p. 48), este fato é 
preocupante, pois "deste modo a criança surda acaba recebendo somente fragmentos da língua oral e da língua de sinais, o que é extremamente prejudicial para o desenvolvimento de linguagem do surdo".

Paralelamente a esses acontecimentos, foram iniciadas, nos Estados Unidos, pesquisas linguísticas sobre as línguas de sinais, com William Stokoe, revelando que essas são línguas naturais. Assim como as línguas orais, as línguas de sinais permitem a expressão do pensamento e apresentam os mesmos níveis de organização formal. Na realidade, o que as diferenciam das línguas audiolinguais é o fato de serem de natureza visuoespacial (QUADROS; CRUZ, 2011).

A partir da década de 1980, surgiu a filosofia educacional denominada Bilinguismo que percebeu a necessidade de valorização da cultura dos surdos, da língua de sinais e de sua não utilização simultânea com a língua oral (GOLDFELD, 2002). Na abordagem bilíngue, a língua de sinais é apresentada como a L1 (primeira língua) dos surdos, enquanto a língua oral deve ser aprendida na modalidade escrita como segunda língua. Quanto ao desenvolvimento da oralidade, isso se tornou optativo por parte da família, conforme prevê o Decreto 5.626 de 2005.

Um passo importante para o surgimento do bilinguismo no Brasil foi o reconhecimento da Libras como meio legal de comunicação e expressão das comunidades surdas do país, com a Lei 10.436/2002. No entanto, essa abordagem ainda não está totalmente difundida e aplicada nas escolas. Um dos motivos é a falta de profissionais fluentes em Libras para atuarem nas diversas áreas de conhecimento no âmbito educacional.

\section{Aquisição de língua}

Para comunicar ideias, estruturar o pensamento, expressar o que se sente e dialogar com outras pessoas, o homem utiliza-se da linguagem, seja na forma verbal ou através de outras maneiras de comunicação. Ela contribui para expansão da cultura, na qual o sujeito mostra-se capaz de produzir transformações nunca antes imaginadas. A linguagem, ainda, tem sido objeto de pesquisa, de estudos e discussões, o que tem contribuído com aspectos relevantes quanto às falhas recorrentes de danos cerebrais ou de distúrbios sensoriais como a surdez. 
Segundo o Behaviorismo, abordagem psicológica surgida no início do século $\mathrm{XX}$, nos Estados Unidos, cujo objeto de estudo consiste no Comportamento animal e humano, a aquisição da linguagem acontece a partir da experiência que a criança desenvolve com a língua utilizada pelas pessoas que estão a sua volta. Conforme essa abordagem, a criança ao nascer é considerada uma tabula rasa, ou seja, sem nenhum conhecimento inato, mas pronta para ser moldada pelo meio no qual está inserida (QUADROS; FINGER, 2008).

No fim da década de 1950, em reação aos behavioristas, surgem os estudos sobre processos e mecanismos de aquisição da linguagem, os quais apontam para o surgimento do Gerativismo, do linguista americano Noam Chomsky. Segundo alguns pesquisadores, a abordagem gerativista é considerada uma corrente inatista, que se caracteriza pela busca de esclarecimento das línguas naturais e o conhecimento de que o ser humano dispõe ao utilizá-las (QUADROS; FINGER, 2008).

Diferentemente do conceito de tabula rasa, Chomsky acredita que o ser humano nasce com um dispositivo inato para desenvolver a linguagem. No entanto, é necessário o input, estímulos linguísticos favoráveis a esse desenvolvimento. Esse dispositivo, segundo Chomsky, consiste na Faculdade de Linguagem, que é um módulo cognitivo independente, especificamente associado à língua, o qual deve ser o objeto central de estudo de uma teoria linguística. Toda criança, surda ou ouvinte, de qualquer lugar do mundo, parte do mesmo estado inicial em seu processo de aquisição da primeira língua. Esse estado inicial da Faculdade de Linguagem chama-se Gramática Universal (GU) que objetiva descobrir os princípios e os elementos comuns das línguas humanas (QUADROS; FINGER, 2008).

Para a Gramática Gerativa, a língua pode ser comparada a um ser vivo: ao nascer traz em seus genes a capacidade de crescer, de se desenvolver e amadurecer. Se receber nutrientes, cresce e se desenvolve, caso contrário, não sobreviverá. O mesmo acontece com a informação genética da Faculdade de Linguagem. Em seu estado inicial, precisa receber nutrientes, ou seja, precisa ser exposta a um ambiente linguístico favorável, para que a criança venha adquirir uma língua. Sendo assim, o contexto linguístico, no qual a criança surda se encontra inserida, será determinante para sua aquisição de linguagem. Todavia, se não houver o input adequado, poderá ocorrer atraso linguístico ou outras sequelas (QUADROS; CRUZ, 2011). 
Conforme a Abordagem Gerativista, as crianças, no processo de aquisição de linguagem, passam por três estágios: período pré-linguístico, período linguístico e período crítico. No período pré-linguístico são observados o balbucio silábico (nos primeiros meses de vida, o bebê produz sons que não apresentam nenhum significado, iniciando com vogais anteriores e consoantes guturais e somente por volta dos seis meses o padrão silábico do balbucio passa a ter uma organização consoante e vogal); o balbucio manual, que ocorre tanto nos bebês surdos quanto nos ouvintes. A diferença é que, num determinado momento, as vocalizações são interrompidas nos bebês surdos, da mesma forma que as produções manuais o são nos bebês ouvintes (QUADROS; CRUZ, 2011). Na ausência de input, o desenvolvimento da linguagem será comprometido.

No chamado "período linguístico" observam-se três estágios: o de uma palavra, de duas palavras e o das múltiplas combinações. O estágio de uma palavra ocorre por volta de um ano de idade, quando as crianças começam a produzir suas primeiras palavras. Normalmente essas palavras estão diretamente relacionadas ao seu ambiente linguístico (“mamãe”, "papai”, “água”, "bola”...). No caso da aquisição da Libras, esse estágio é denominado estágio de um sinal, um nível em que "a criança imita sinais produzidos pelos outros, apesar de apresentar configurações de mão e movimentos imperfeitos. Ela pode chegar a usar alguns sinais com significado consciente" (QUADROS; CRUZ, 2011, p. 19). O segundo estágio do período linguístico é chamado "de duas palavras" e ocorre no segundo ano de vida, quando a criança passa a combinar duas ou mais palavras. Não há como determinar o momento exato a partir do qual ela passa a produzir tais combinações. Em aquisição de língua, no estágio das primeiras combinações, ela começa a combinar dois sinais, a partir da sinalização dos adultos, por exemplo: QUERER ÁGUA (QUADROS; CRUZ, 2011, p. 20). No terceiro estágio, o das múltiplas combinações, acontece uma "explosão" de vocabulário, tanto de palavras quanto de sinais, pois a criança já começa a usar pequenas frases e a classificar as palavras, utilizando-as apropriadamente e selecionando as desinências para derivá-las de modo apropriado (aproximadamente aos 4 anos).

O terceiro estágio, de acordo com a Abordagem Gerativista, é o Período Crítico, que se inicia por volta dos 2 anos e se prolonga até a puberdade. Esse período pode ser entendido como o "pico" do processo de aquisição da linguagem. No caso das crianças 
surdas, a grande maioria nasce em família de ouvintes, que desconhecem a língua de sinais e, em alguns casos, nunca tiveram contato com um surdo. Isso interfere diretamente no processo de aquisição de linguagem e, até que os pais tomem conhecimento da língua de sinais, essas crianças ficam sem input linguístico. Dessa forma, elas sofrem prejuízos e atrasos de linguagem, o que, consequentemente, acarreta déficit cognitivo. Na ausência de uma língua "muitas dessas crianças surdas criam um sistema gestual para se comunicarem com seus pais, chamados também de sinais caseiros" (QUADROS; CRUZ, 2011, p. 25).

Além das contribuições de Chomsky sobre a importância de um ambiente linguístico favorável para a aquisição da linguagem, Vygotsky (1984) afirma que o ser humano necessita da interação social, para o pleno desenvolvimento de suas funções psicológicas superiores e mentais. Segundo Vygotsky, a linguagem está diretamente relacionada ao pensamento, por meio do qual é possível lidar com objetos do mundo exterior, nomear, analisar, abstrair e perceber características desses objetos presentes na realidade. Nessa perspectiva, a linguagem é atividade constitutiva do conhecimento de mundo e a criança se constrói como sujeito. Sem linguagem, o ser humano não é social, nem histórico, nem cultural (QUADROS; FINGER, 2008).

Vários estudos comprovam que crianças surdas expostas a ambientes linguísticos favoráveis mediados por adultos surdos ou mesmo por ouvintes que utilizam a língua de sinais, se desenvolvem linguística e cognitivamente tão bem quanto qualquer criança ouvinte. A aquisição de uma língua é fundamental para que a criança construa conceitos e significados e obtenha sua visão de mundo. Quando há a conscientização sobre a necessidade que a criança surda tem de adquirir uma língua visual e quando os pais reconhecem a importância de também aprender tal língua para se comunicarem com o seu filho, isto favorecerá um desenvolvimento linguístico mais adequado (QUADROS; CRUZ, 2011).

\section{Metodologia}

O presente estudo é de natureza descritivo-analítica, com abordagem qualitativa realizada em campo, considerando a experiência e a vivência dos participantes. A proposta inicial seria a entrevista de pelo menos cinco profissionais, mas devido 
indisponibilidade de alguns, foi possível realizar apenas duas: uma com um médico otorrinolaringologista e a outra com uma fonoaudióloga.

A coleta de dados foi realizada no período de 20 a 25 de setembro de 2014 e teve como instrumentos uma entrevista estruturada com perguntas abertas e um questionário. As respostas das entrevistas foram gravadas em áudio e posteriormente transcritas para o português. O questionário, com quatro questões, teve o objetivo de verificar: 1) a orientação dada à família a respeito da modalidade de comunicação a ser adotada diante um diagnóstico de surdez; 2) o conhecimento dos profissionais sobre a Libras; 3) o tipo de comunicação utilizado pelos pacientes com perda auditiva; 4) a forma de adaptação dos pacientes ao A.A.S.I (Aparelho de Amplificação Sonora Individual) ou ao implante coclear.

\section{Resultados e discussão}

Os resultados obtidos pela pesquisa mostraram pontos de vista contrários em alguns pontos. Conforme apresentado abaixo:

\section{Quadro 1 - Orientação sobre comunicação}

1) Diante de um diagnóstico de surdez, qual a orientação dada à família, sobre a comunicação?

\begin{tabular}{|c|c|}
\hline OTORRINOLARINGOLOGISTA & FONOAUDIÓLOGA \\
\hline $\begin{array}{l}\text { Hoje, os otorrinos têm um enfoque muito } \\
\text { grande para cirurgia, [...] até dois anos de } \\
\text { idade, nós vamos orientar fortemente esse } \\
\text { paciente para a realização do implante } \\
\text { coclear. } \\
\text { [...] Indicamos Libras para pacientes } \\
\text { adolescentes, adultos e para aqueles que a } \\
\text { indicação do implante coclear tem restrições. }\end{array}$ & $\begin{array}{l}\text { Internalizar conceitos, dar significado para a } \\
\text { criança surda através da Libras, favorece o } \\
\text { desenvolvimento da oralidade também. } \\
\text { Atendo crianças que são felizes usando } \\
\text { somente a Libras e não manifestam desejo em } \\
\text { falar. [...] mas explico a importância da LOF } \\
\text { (Leitura Orofacial) [...]. }\end{array}$ \\
\hline
\end{tabular}

A orientação do médico mostra-se tendenciosa para a abordagem clínica do reparo e percebe a língua de sinais como último recurso ou quando o tratamento clínico (leia-se, cirurgia) não é eficaz. Infelizmente, o "discurso médico tem muito mais força e 
prestígio do que o discurso da diversidade, do reconhecimento linguístico e cultural das minorias surdas" (GESSER, 2009, p. 67). Além disso, a maioria dos casos de surdez acontece em lares cujas famílias são ouvintes, as quais desconhecem o histórico dos surdos, bem como sua língua e suas reais necessidades. Outro ponto positivo para que o sujeito surdo aprenda a falar seria a comodidade, pois dessa forma, o surdo é quem terá de se adaptar ao meio ouvinte e não o contrário.

A fonoaudióloga, por sua vez, mostra-se favorável á língua de sinais, mas considera importante o surdo conseguir fazer a leitura orofacial, o que implica em conhecer a língua oral da comunidade onde está inserido. A aquisição sistemática da língua oral, no caso do Brasil o português, não se compara à aquisição natural e contextualizada da língua de sinais, num ambiente linguístico favorável.

Apesar de todas as conquistas obtidas pelas comunidades surdas no Brasil, como o reconhecimento da Libras, a partir da criação da Lei $n^{\circ} 10.436 / 02$, regulamentada pelo Decreto 5626/05, a surdez, para a grande maioria ouvinte, ainda é vista sob a ótica da deficiência. Contudo, se olhada pelo viés cultural, terá outra conotação, a de diferença. Longe do paradigma patológico, os sujeitos surdos não são inferiores aos ouvintes, eles apenas concebem o mundo de um jeito peculiar, ou seja, através da visão. Sendo assim, utilizam a língua de modalidade visual-gestual nos contextos de comunicação e se apropriam de alguns artefatos inerentes à sua cultura, ao seu jeito surdo de viver e de interagir com o mundo (STROBEL, 2008).

Sabe-se que a família é de suma importância no diagnóstico de surdez de seus filhos e que ela pode contribuir significativamente para seu aprendizado da Libras, porém existe uma dificuldade na transmissão de valores paternos e há também o predomínio da língua oral no núcleo familiar.

De um modo geral, a mãe ouvinte brasileira usa língua portuguesa oral, mesmo que esteja aprendendo a língua de sinais. Em nossa experiência observamos também que quando a criança surda não tem um domínio da língua oral, muitas vezes as mães sinalizam e falam ao mesmo tempo, utilizando a Comunicação Total. (LITCHING; COUTO; CÁRNIO, 2000). 
Uma orientação familiar adequada, no que se refere à língua de sinais e à cultura surda, mostra-se, portanto, fundamental para construção da identidade surda. Sobre o conhecimento que os participantes têm da Libras, foram obtidos os seguintes resultados:

\section{Quadro 2 - LIBRAS como meio de comunicação}

2) Você conhece a Libras? Sabe se comunicar em Libras?

\begin{tabular}{|c|c|}
\hline OTORRINOLARINGOLOGISTA & FONOAUDIÓLOGA \\
\hline $\begin{array}{l}\text { Conheço Libras, mas não me comunico } \\
\text { por Libras, não aprendi. } \\
\text { Libras é uma língua de sinais, que a } \\
\text { pessoa consegue desenvolver através de } \\
\text { sinais. }\end{array}$ & $\begin{array}{l}\text { Trata-se de uma língua como outra qualquer, só } \\
\text { que na modalidade visuo-espacial o que a difere } \\
\text { das línguas orais auditivas. } \\
\text { Conheço a LIBRAS e sei me comunicar através } \\
\text { dela. }\end{array}$ \\
\hline
\end{tabular}

Na maioria das vezes, aqueles que defendem o método Oral desconhece a língua de sinais, bem como a comunidade surda e sua cultura. Não entendem que a pessoa surda tem uma forma peculiar de conceber o mundo e de interagir com ele. Dessa forma, acreditam que a aquisição da língua oral, mesmo com sofrimento, é o ideal para que o surdo se desenvolva e interaja em um mundo dominado por sons. Desconhecem também que é através do contato e das trocas com outras pessoas surdas que ele vai construir sua subjetividade e, consequentemente, sua identidade. Quando uma criança surda é privada dessa interação, infelizmente, ela sofrerá atraso de linguagem e déficit cognitivo, o que lhe acarretará muitas perdas durante toda sua vida.

Apesar de a aprendizagem da língua oral também ter sua importância para a autonomia da pessoa surda em contextos onde a língua de sinais não é conhecida, de acordo com Goldfeld (2002, p. 45), a língua de sinais "seria a única língua que o surdo poderia dominar plenamente e que serviria para todas as suas necessidades de comunicação e cognitivas". Em relação à forma de comunicação utilizada pelos pacientes com perda auditiva, os resultados foram:

\section{Quadro 3 - Comunicação de pacientes com perda auditiva}

3) Como seus pacientes com perda auditiva se comunicam?

\begin{tabular}{|c|c|}
\hline OTORRINOLARINGOLOGISTA & FONOAUDIÓLOGA \\
\hline Quando a perda auditiva não é tão intensa & A grande maioria faz o uso da LIBRAS, alguns \\
\hline
\end{tabular}


eles vão se comunicar oralmente e fazendo leitura labial. [...]. Em relação aos pacientes que tem perda profunda, eles vão se comunicar por Libras. Geralmente, só comunica por Libras o paciente com a perda profunda que nem o aparelho auditivo está conseguindo fazer algo por ele. [...]. surdos com perdas leves e moderadas oralizam. Há um caso de um surdo profundo que usa libras e oraliza também.

Gesser (2009) relata que o surdo não precisa ser oralizado para se integrar na sociedade ouvinte, pois para muitos a busca pela recuperação da audição, bem como da fala vocalizada foi razão de muito sofrimento, dor e opressão. Para os defensores do oralismo, a língua é percebida "somente como um código formado por regras gramaticais que tem por objetivo final a comunicação" (GOLDFELD, 2002, p. 97). Sendo assim, eles se esquecem do fator aquisição de linguagem, e de sua importância no desenvolvimento cognitivo e emocional da criança surda.

A quarta e última pergunta da entrevista se refere à forma como os pacientes se adaptam ao aparelho auditivo ou ao implante coclear. As respostas obtidas foram as seguintes:

\section{Quadro 4 - Adaptação ao Aparelho Auditivo}

4) Como é a adaptação de seus pacientes ao Aparelho Auditivo ou Implante Coclear?

\begin{tabular}{|c|c|}
\hline OTORRINOLARINGOLOGISTA & FONOAUDIÓLOGA \\
\hline $\begin{array}{l}\text { Um paciente que apresenta uma perda } \\
\text { condutiva [...] que é uma perda grande, vai ter } \\
\text { uma adaptação fantástica ao aparelho } \\
\text { auditivo. Enquanto os pacientes que } \\
\text { apresentam uma surdez congênita, ou uma } \\
\text { surdez por envelhecimento [...] mesmo eu } \\
\text { colocando o aparelho auditivo que } \\
\text { proporciona a eles uma maior intensidade } \\
\text { sonora, eles terão uma dificuldade para } \\
\text { reconhecer... } \\
\text { Vai para o implante o paciente que não se } \\
\text { adaptou bem ao aparelho auditivo, que não } \\
\text { tem indicação pra isso e costuma ter um } \\
\text { ganho satisfatório. }\end{array}$ & $\begin{array}{l}\text { Geralmente os educandos, com perda auditiva } \\
\text { de grau profundo, não se adaptam bem. [...] } \\
\text { não gostam de fazer uso do AASI. Já os } \\
\text { educandos com perdas de grau leve a } \\
\text { moderado se beneficiam bastante do uso do } \\
\text { AASI e demonstram melhor adaptação... } \\
\text { [...] as pessoas se esquecem que após o } \\
\text { implante será necessário um novo } \\
\text { aprendizado das habilidades auditivas e que, } \\
\text { portanto, necessita de intervenção em longo } \\
\text { prazo. }\end{array}$ \\
\hline
\end{tabular}


Para os adeptos da filosofia Oralista, a surdez é entendida como uma patologia, a qual precisa ser medicalizada. Por meio da A.A.S.I (aparelho de amplificação sonora individual) ou do implante coclear, a pessoa surda será reabilitada em direção à normalidade, à não-surdez, o que a levará à integração à comunidade ouvinte. Só em casos de surdez profunda, somente quando não há nenhum resíduo auditivo, é que o paciente é orientado a utilizar a Libras (Língua Brasileira de Sinais) (GESSER, 2009).

Quanto ao implante coclear, o médico defende que os pacientes implantados seguem a vida normalmente. Portanto, de acordo com Gesser (2009), além de o método para colocação do implante ser muito invasivo, "o resultado é sempre drástico", uma vez que o sucesso do resultado dependerá de uma série de implicações. E, nem sempre a satisfação será expressiva.

\section{Considerações finais}

Com base nos dados, a pesquisa mostrou divergências entre as opiniões sobre a orientação que deve ser dada à família diante um diagnóstico de surdez. Percebeu-se que, de acordo com a visão do médico otorrinolaringologista, a principal indicação está voltada à oralização e correção da surdez, seja pelo uso de aparelhos, ou através do implante coclear, que no caso vai depender da idade e do grau de surdez do paciente. Todavia, conforme a fonoaudióloga, o caminho mais adequado seria a aquisição da Libras, pois esta, além de proporcionar o desenvolvimento da criança, também atende suas necessidades comunicativas.

Mesmo após a constatação a respeito da importância da língua de sinais para o desenvolvimento cognitivo e social das pessoas surdas, ainda hoje o desconhecimento dessa língua e de sua relevância tem levado profissionais da saúde a indicar tratamento clínico-corretivo às famílias cujos filhos são surdos. Muitas dessas famílias, por razões diversas como o desconhecimento sobre a língua de sinais, a negação da surdez na família, a esperança na recuperação da fala, entre outras coisas, seguem a orientação médica e buscam na oralização, a medicalização e erradicação da surdez.

Por outro lado, há aqueles profissionais que, a partir da vivência com os surdos, compreendem a ausência da audição não como uma patologia a ser tratada, mas como um jeito diferente dessas pessoas serem e de conceberem o mundo através da visão. À 
medida que essa convivência é estreitada, é possível perceber que os surdos possuem uma cultura própria e um jeito peculiar de ser. Contrariando a sociedade ouvinte, a maioria dos surdos não sente necessidade de oralizar, pois encontra na língua de sinais o meio mais fácil e mais eficaz de expressarem suas ideias, opiniões, seus desejos, anseios e valores.

\begin{abstract}
This article aims at investigating the guidance of speech therapists and otorhinolaryngologists about language acquisition, as well as evaluating these professionals' different conceptions about sign language when faced with a diagnostic of deafness. The qualitative analysis research was done by means of a structured interview and questionnaire with open-ended questions. The data analysis showed that these professionals diverge when it comes to the guidance offered these patients' families. For the otorhinolaryngologist, depending on the type and level of deafness, it is possible to use hearing aids or a cochlear implant, which makes clear their preference for an oralist approach, while the speech-language pathologist recommends the use of Libras.
\end{abstract}

Key words: sign language, Deaf, deafness diagnosis.

\title{
Resumen
}

Este artículo tiene el objetivo de investigar la orientación de los médicos otorrinolaringologistas y fonoaudiólogos sobre la adquisición de una lengua y también la concepción de esos profesionales sobre la lengua de señas ante un diagnóstico de sordez. La investigación, de enfoque cualitativo, fue desarrollada a través de una entrevista estructurada y un cuestionario con preguntas abiertas. El análisis de los datos demostró que hay desacuerdo entre las opiniones con relación a la orientación dada a las familias de los pacientes. Para el otorrinolanringologista, dependiendo del tipo y grado de sordez, es posible el uso del aparato auditivo o la realización del implante coclear, dejando clara su opción por una orientación de cuño oralista, mientras la fonoaudióloga recomienda el uso de LIBRAS.

Palabras-clave: lengua de señas, Sordo, diagnóstico de sordez.

\section{Referências}

BRASIL. Decreto $n^{\circ}$ 5.626, de 22 de dezembro de 2005. Regulamenta a Lei $\mathrm{n}^{\circ} 10.436$, de 24 de abril de 2002, que dispõe sobre a Língua Brasileira de Sinais - Libras, e o art. 18 da Lei no 10.098, de 19 de dezembro de 2000. Diário Oficial [da] União, Brasília, DF, 23 dez. 2005. Disponível em: http://www.planalto.gov.br/ccivil_03/_ato20042006/2005/decreto/d5626.htm. Acesso em: 24 mar. 2016. 
Lei $\mathrm{n}^{\mathrm{o}}$ 12.319/2010. Regulamenta a profissão de Tradutor e Intérprete da

Língua Brasileira de Sinais - LIBRAS. Diário Oficial [da] União, Brasília, DF, 2 set.

2010. Disponível em: http://www.planalto.gov.br/ccivil_03/_Ato2007-

2010/2010/Lei/L12319.htm . Acesso em: 24 mar. 2016.

GESSER, A. Libras, que língua é essa? São Paulo: Parábola, 2009.

GOLDFELD, M. A criança surda: linguagem e cognição numa perspectiva sociointeracionista. 2. ed. São Paulo: Plexus, 2002.

HONORA, M.; FRIZANCO, M. L. E. Livro ilustrado de Língua Brasileira de

Sinais: desvendando a comunicação usada pelas pessoas com surdez. São Paulo:

Ciranda Cultural, 2009.

LITCHING, I. da; COUTO, M. I. V.; CÁRNIO, M. S. Linguagem e Surdez. In:

LACERDA, C. B. F. de; NAKAMURA, H.; LIMA, M. C. (Org.) Fonoaudiologia, surdez e abordagem bilíngue. São Paulo: Plexus, 2000. p. 44-55.

MONTES, R. F. dos; SANTOS, I. B. dos. Saberes e práticas da inclusão: dificuldades de comunicação e sinalização: surdez. Brasília: MEC/SEESP, 2004. 89 p.

QUADROS, R. M.; CRUZ, C. R. Língua de Sinais: instrumentos de avaliação. Porto Alegre: Artmed, 2011.

QUADROS, R. M.; FINGER, I. Teorias de aquisição da linguagem. Florianópolis: Editora da UFSC, 2008. Cap. 2.

SKLIAR, C. (Org.). A surdez: um olhar sobre as diferenças. 3. ed. Porto Alegre: Mediação, 1998.

STROBEL, k. As imagens do outro sobre a cultura surda. Florianópolis: Ed. UFSC, 2008 .

VIGOTSKY, L. S. A formação social da mente: o desenvolvimento dos processos psicológicos superiores. São Paulo: Martins Fontes, 1984. 